\title{
Estimation of the Quality-of-Life Impact of X-Linked Myotubular Myopathy
}

\author{
Andrew Lloyd ${ }^{\mathrm{a}, *}$, Daniel Aggio ${ }^{\mathrm{a}}$, Ted L. Slocomb ${ }^{\mathrm{b}}$, Jun Lee ${ }^{\mathrm{d}}$, Alan H. Beggs and Deborah A. Bilder \\ ${ }^{a}$ Acaster Lloyd Consulting Ltd., London, UK \\ bAstellas Gene Therapies, San Francisco, CA, USA \\ ${ }^{\mathrm{c}}$ Fomerly Astellas Gene Therapies, San Francisco, CA, USA \\ ${ }^{\mathrm{d}}$ Division of Genetics and Genomics, The Manton Center for Orphan Disease Research, Boston Children's \\ Hospital, Harvard Medical School, Boston, MA, USA \\ ${ }^{\mathrm{e}}$ University of Utah, Salt Lake City, UT, USA
}

Pre-press 6 July 2021

\begin{abstract}
X-linked myotubular myopathy (XLMTM) is a rare, severe, neuromuscular disorder for which novel treatments are under investigation. This study estimated quality-of-life weights (or utilities) for children with XLMTM. The state that was rated the worst described a child unable to sit and requiring invasive ventilation for $\geq 16$ hours a day (utility $=-0.07$ or -0.27 depending on method used). The state describing a child who can stand and walk and does not require invasive ventilation was the most highly rated state and had a utility of 0.91 or 0.77 (depending on method used).

Nine health state vignettes were developed for XLMTM defined in terms of respiratory and motor function based on clinical trial data from parents completing the Assessment of Caregiver Experience with Neuromuscular Disease (ACEND) Domain 1 scale assessing mobility, transfers, sitting, playing, eating, grooming and dressing. These data were supplemented with qualitative data from parent interviews on the daily impact of XLMTM, especially in terms of psychological wellbeing, pain and discomfort, and communication. Seven clinical experts reviewed the draft vignettes for accuracy. Vignettes were rated by members of the UK general public using a time trade-off (TTO) interview and an EQ-5D-5L assessment. This study demonstrated a substantial impact of XLMTM on utility weights.
\end{abstract}

Keywords: X-linked myotubular myopathy, health state utilities, EQ-5D-5L, gene replacement therapy

\section{INTRODUCTION}

X-linked myotubular myopathy (XLMTM) is a primary congenital myopathy caused by pathogenic variants in the MTM1 gene encoding the protein myotubularin, resulting in a lack or dysfunction of myotubularin, which is needed for normal development, maturation and maintenance of skeletal muscle cells $[1,2]$. This rare neuromuscular disorder has an estimated incidence of 1/40,000 male births [3]. XLMTM presents at birth and is characterised by severe muscle weakness, hypotonia, and respiratory

\footnotetext{
${ }^{*}$ Correspondence to: Andrew Lloyd, Acaster Lloyd Consulting Ltd., London, UK. Tel.: +44 07793222 377; E-mail: andrew.lloyd@acasterlloyd.com.
}

failure. Survival and prognosis are typically poor [4], primarily due to respiratory insufficiency [5]. Median survival time in children under 5 years of age requiring respiratory support is 2.2 years [5]. In those surviving infancy, XLMTM is associated with considerable disease burden. Nearly half require 24-hour ventilatory support and many require wheelchairs, feeding tubes, and multiple surgeries [5-7]. In addition, XLMTM is a progressive disease in which patients who have acquired a specific motor milestone may lose it, and a small but significant decline can be recorded using motor scales over a one-year period [8].

There are currently no approved disease-modifying therapies for XLMTM. A gene therapy (AT132 
[resamirigene bilparvovec], Astellas Gene Therapies (fomerly Audentes Therapeutics)) is in development as a one-time administration of a functional copy of MTM1 delivered by an adeno-associated virus serotype 8 (AAV8) vector. The first children to receive this treatment in the ASPIRO (NCT03199469) clinical trial have shown sustained and continuous improvements in respiratory and motor function [9]. However, detailed data regarding the impact of untreated XLMTM on health-related quality-of-life are not available.

Estimating utility weight of health states associated with rare diseases is a methodological challenge. The utilities for a health state are assumed to reflect or be representative of all XLMTM patients with that specific level of motor and respiratory function. A mean value and associated confidence interval are needed to better understand the potential variability within a health state. An optimal approach would be to administer a generic quality-of-life measure, such as the EQ-5D-5L to all XLMTM patients in a study. Although this approach would produce the necessary data to estimate quality-adjusted life years (QALYs), severe motor and communication impairments resulting from XLMTM would necessitate proxy-rated completion (i.e., an unaffected individual providing responses about the affected individual or as if they were the affected individual), and its use for children aged 5 years and younger still requires validation. Such a dataset would also be limited by the small size of the current XLMTM studies and the use of delayed-treatment control rather than placebo control in the ASPIRO trial [9]. It is also unclear whether any of the available preference-weighted measures of health (e.g., EQ-5D-Y, CHU-9D, HUI-3) are suitable for use in children with XLMTM.

This study aimed to estimate utility weight of health states associated with XLMTM, defined in terms of respiratory and motor function, to support future cost-effectiveness analyses.

\section{METHODS}

\section{Study design}

The study was conducted in two phases. In the first phase, vignettes were developed for nine health states using data from an existing outcome measure and qualitative information from parents and clinical experts. In the second phase, utilities for each state were estimated using the time-trade-off (TTO) interviews method with the UK general public. All participants provided informed consent as per the Helsinki Declaration.

\section{Health state vignette development}

Nine health states were defined in terms of respiratory support and motor functioning. Respiratory support was defined in terms of three levels: tracheostomy or non-invasive ventilatory support for over 16 hours per day (a key functional and clinically relevant cut-off) [10], tracheostomy or non-invasive ventilatory support for less than 16 hours per day, and no ventilatory support required. Similarly, motor function was defined in terms of three levels: not able to sit independently, able to sit independently, and able to stand/walk.

This classification was guided by input from expert clinicians and an independent health economic modelling team. The vignette content was based on analysis of data from the Assessment of Caregiver Experience with Neuromuscular Disease (ACEND) measure used in the ASPIRO trial [9], qualitative data from an existing study (data not published, internal Astellas Gene Therapies study), and data from a series of new interviews with families affected by XLMTM. Lastly, a series of interviews were conducted with clinical experts to review draft study materials and to provide feedback on final changes to the content of the vignettes.

\section{Analysis of ASPIRO trial data}

\section{Data sources}

The ASPIRO trial is a phase $1 / 2$, open-label trial examining the safety and efficacy of AT132 in children with XLMTM (aged $>5$ years at day 1 of ASPIRO and/or participated in INCEPTUS, NCT02704273, a prospective run-in study to inform clinical endpoints for ASPIRO) [9]. After dosing, patients' motor and respiratory function were assessed on a regular basis, allowing for categorization of model health states. At the time of this study, longitudinal data collected up to 72 weeks post treatment were available for 12 study participants (which included the 2 undosed control patients). At follow up visits, caregivers completed the ACEND questionnaire (Week 0, 1, 2, 4, 12, 16, 24, 36, 48, 72 but not all time points for all participants). ACEND assesses areas of functioning including sitting, feeding, transfers, washing, dressing, and walking, as reported by caregivers of children aged 4-19 years 
Table 1

ACEND structure and initial health state domains

\begin{tabular}{|c|c|}
\hline ACEND DOMAIN & ACEND ITEM* \\
\hline $\begin{array}{l}\text { Feeding/ } \\
\text { grooming/dressing }\end{array}$ & $\begin{array}{l}\text { Does your } \\
\ldots \text { child finger feed? } \\
\ldots \text { use a spoon to eat? } \\
\ldots \text { lift a cup securely and drink? } \\
\ldots \text { wash his/her hands thoroughly? } \\
\ldots \text { remove his/her socks and } \\
\quad \text { unfasten shoes? } \\
\ldots \text { remove his/her dress, t-shirt or sweater? }\end{array}$ \\
\hline Sitting/play & $\begin{array}{l}\ldots \text { sit for } 1-15 \text { minutes on a chair? } \\
\ldots \text { sit for more than } 15 \text { minutes on a chair? } \\
\ldots \text { manipulate toys or objects? } \\
\ldots \text { reach and grab toys or objects? } \\
\ldots \text { play safely at home for } 10 \text { minutes? }\end{array}$ \\
\hline Transfers & $\begin{array}{l}\ldots \text { turn/roll over to side of the bed? } \\
\ldots \text { get in and out of bed? } \\
\ldots \text { get in and out of chair? } \\
\ldots \text { get in and out of bathtub? } \\
\ldots \text { get in and out of car? }\end{array}$ \\
\hline Mobility & $\begin{array}{l}\ldots \text { roll, scoot or crawl on the floor? } \\
\ldots \text { walk but hold onto furniture? } \\
\ldots \text { walk } 10 \text { steps or more? } \\
\ldots \text { move up and down the stairs by } \\
\text { scooting, crawling and/or walking? } \\
\ldots \text { move within a room? } \\
\ldots \text { move between rooms? } \\
\ldots \text { move over rough/uneven } \\
\text { surfaces outdoors? }\end{array}$ \\
\hline
\end{tabular}

${ }^{*}$ Responses options presented in Fig. 1.

[11]. All ACEND data from every available visit was included in the analysis.

ACEND consists of a physical and a general domain. The physical domain includes four subdomains (feeding/grooming/dressing; sitting/play; transfer; mobility), each with six response options
(Table 1). These subdomains informed the initial concepts included in the health state descriptions. Table 2 shows how the ACEND domains were modified to make the language more appropriate for British adults in the study (e.g. feeding/grooming/dressing were modified to eat/wash/dress).

\section{Analyses}

Descriptive analyses were performed to determine the frequency that each ACEND response option was endorsed. This was summarised separately for the nine health states in terms of modal responses to each item in the ACEND. The least severe health states were less commonly reported, with no ACEND data available at all for the following three health states: unable to sit independently with no ventilatory support; able to stand/walk with non-invasive ventilation < 16 hours/day; and able to stand/walk with no ventilatory support). The most frequently occurring response option endorsed for each ACEND item for each health state was included in the vignette description. For some health states two response were equally reported in frequency. The modal responses for a selection of items on the ACEND for each health state is shown in Fig. 1.

\section{Qualitative analysis of parent interviews}

Qualitative data from existing and new parent interviews were used to provide additional information to guide vignette development. In one set of exploratory interviews (Astellas Gene Therapies,

Table 2

Concepts important to XLMTM patients as reported by parents

\begin{tabular}{|c|c|}
\hline Comment/topic & Illustrative quote/source \\
\hline Speech difficulties & "the caregiver reported that her son ... can verbalize monosyllabic words" (parent 1) \\
\hline Pain/discomfort & $\begin{array}{l}\text { "I did this practice [physiotherapy exercises] with him and I know how he hated that, so you } \\
\text { basically do something that is really painful, that was painful for him" (parent } 8^{*} \text { ) }\end{array}$ \\
\hline $\begin{array}{l}\text { Psychological } \\
\text { impact/emotions }\end{array}$ & $\begin{array}{l}\text { “... he is trying to say something very specific and he can't think of a way to rephrase it or a } \\
\text { way to describe it, but it doesn't make sense what he's saying and he gets very } \\
\text { frustrated..." (parent } 5 \text { ) }\end{array}$ \\
\hline Ventilation & $\begin{array}{l}\text { "... that has changed a lot over the years of how much he can tolerate being off [a ventilator], } \\
\text { but he's still very dependent" (parent } 2 \text { ) }\end{array}$ \\
\hline Grasp & "he doesn't really have a very strong grasp, so he can't hold heavy objects at all (parent 2)" \\
\hline GI tube feeding & $\begin{array}{l}\text { "he is ventilator dependent and has a permanent GI tube for all nutritional and hydration } \\
\text { needs" (parent 5)" }\end{array}$ \\
\hline Toileting issues & "he's unable to go to the restroom so they change him with a diaper" (parent $6^{*}$ ) \\
\hline $\begin{array}{l}\text { Physical therapy/ } \\
\text { treatment to clear } \\
\text { airways }\end{array}$ & $\begin{array}{l}\text { "to begin the day we start with breathing treatment, which consists of a nebulizer treatment, a } \\
\left.\text { progressive vest treatment for the last twenty minutes, a cough assist ... (parent } 6^{*}\right) \text { ") }\end{array}$ \\
\hline Assistive devices & $\begin{array}{l}\text { "and because he has gotten older and has more equipment to support him like the wheelchair } \\
\text { and the communication tablet..." (parent 5) }\end{array}$ \\
\hline
\end{tabular}

*Additional parents of children with XLMTM were interviewed specifically for this study to further explore the different ways in which the condition affects children's lives. 


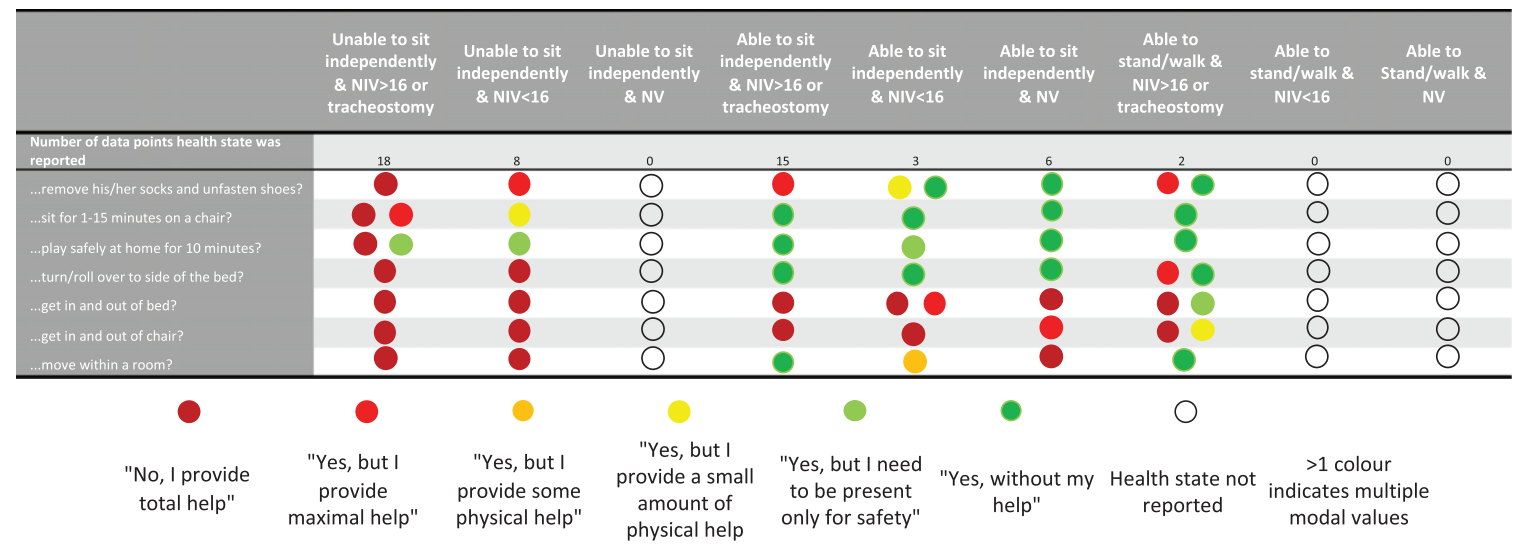

Fig. 1. Modal values for selected ACEND items according to health states. (NIV= Non-invasive ventilation; NV= No ventilation). The colored dots represent different parent responses to questions on the ACEND questionnaire, as noted in the legend below the table.

data on file), five parents of children with XLMTM (labelled as Parents 1-5 in Table 2) were interviewed to gain a deeper understanding of how XLMTM impacts the health-related quality-of-life (HRQL) of affected children. These data were summarised into broad areas of HRQL, including symptom experience, specific milestones, impact on daily life, emotional/psychological function, and quality-of-life. All participants rated their child's condition as moderate to severe.

In addition, five parents of children with XLMTM were interviewed specifically for this study (Parents 6 to 10) to further explore the different ways in which the condition affects children's lives. The study interview guide explored different aspects of the child's life: the typical daily routine, respiratory support and clearing airways, supervision, experience of pain and discomfort, physical mobility or function, usual activities, preferred activities, cognitive function, and communication. Parents were also asked to indicate how severely affected they believed their child was. After these exploratory questions, parents were shown draft health state vignettes based in part on the ACEND data and reflecting a previously published health state in spinal muscular atrophy [12]. Parents were asked to comment on the appropriateness of the draft description as a description of their child.

The interview data were combined and analyzed collectively, and findings were used to guide the content of the vignettes. The interviews identified issues that were not present in the ACEND data. Three additional domains (psychological/communication, pain/discomfort, and ventilation) were added to the vignettes. Other more specific items were also added to describe difficulties with grasping objects, feeding/swallowing, toileting, bed sores and requirements for physical therapy and assistive devices. Illustrative quotes are provided in Table 2.

\section{Draft health states}

Based on the ACEND data from the ASPIRO trial and the parent interviews, 6 health states were developed. No quantitative or qualitative data were available to describe 3 further states: unable to sit and requiring no invasive ventilation, able to stand/walk and requiring $<16$ hours per day non-invasive ventilation, able to stand/walk and requiring no invasive ventilation. No trial patient or interview participant was classified within one of these 3 health state definitions. Therefore, these health state vignettes were initially drafted by extrapolating information from the more severe health states and were used as the basis of discussions with XLMTM experts.

\section{Qualitative analysis of expert interviews}

Telephone and face-to-face interviews were conducted with 6 XLMTM experts, including physicians and a specialist physical therapist. Each of the experts had many years of experience in caring for children with XLMTM and worked in specialist referral centres. Each expert also had considerable research experience with many publications on XLMTM and related conditions. The draft health state descriptions were distributed to the experts to read prior to the interviews. Interview questions were 
designed to validate and refine the content of the vignettes, as well as identify any other topics that were not covered by the ACEND and qualitative parent interviews. A particular focus of the expert interviews was an assessment of the 3 health states for which no data were available to guide their content. Overall, the experts felt that the health states were accurate descriptions, and no major topics were missing. However, experts did request some changes to the health states. The physical therapy statement was removed because 2 experts suggested that physical therapy would not necessarily correlate with disease severity. Minor wording changes were made to reflect the general consensus that not all patients would experience the symptoms as described, thus there was a risk that the states may be too severe. Other minor wording changes were made for clarity and context.

Other key emerging themes from these interviews were used to modify the health state vignettes, as shown in the appendix.

\section{Health state valuation}

\section{TTO method}

The health utility scale ranges from 1.0 to 0 , where 1 represents full health and 0 represents dead. Full health is a state of health where you are not affected or limited by any health problem, with no problems with mobility, undertaking usual activities, no pain, depression, anxiety or other symptoms. The TTO interview approach was used to value each of the vignette descriptions $[13,14]$. The TTO approach aims to establish for each participant the equivalency between 10 years in an XLMTM health state and a period of time in full health. Time in full health is varied until participants indicate that the 2 prospects or options are the same (e.g., they are indifferent between them).

Time in full health was varied using a 'ping pong' approach, whereby the time in full health was switched back and forth (i.e., from nine years to one year) at six-month intervals. If participants indicated they preferred being dead to living any time in a health state, then this indicated that the participant believed the health state to be worse than dead. Such states were then assessed using the lead-time TTO approach. In these instances, participants were asked to choose between living in full health for 10 years followed by 10 years in the health state or living for 20 years in full health. The point of indifference was then determined using the same 'ping pong' procedure described above but the lead-time approach enables the participant to trade up to 20 years of life, which allows them to indicate how much worse than dead a state is.

\section{Participants}

Members of the UK general public over the age of 18 were recruited using convenience sampling. Recruitment aimed to achieve a representative sample of adults in the UK in terms of age, sex, and ethnicity.

\section{Data collection}

Interviews were conducted by trained field-based interviewers. Prior to the start of the interview, participants were given an information sheet, detailing the purpose of the study and procedures, and a consent form. If participants agreed to take part, they were asked to complete a sociodemographic questionnaire and the EQ-5D-5L about themselves.

Interviews were conducted using the 9 XLMTM health state vignettes, a 'full health state' vignette, a 'dead' vignette (available in the appendix) and 2 practice vignettes. To initiate the interviews, participants were provided with a brief introduction asking them to imagine themselves living with a chronic condition, involving muscle weakness, breathing and eating problems, without explicitly mentioning XLMTM. They were then asked to rank the severity of each vignette from 0 (worst possible state) to 100 (full health) on a visual analogue scale (VAS), including a state simply described as "You are dead." Before ranking the XLMTM health state vignettes, participants were asked to rank 2 practice vignettes to become familiar with the approach and have the opportunity to ask questions. The second practice health state was dropped after the first 3 TTO interviews to reduce participant burden.

After the VAS exercise, participants completed the TTO interview, beginning with the practice vignette, followed by the 9 XLMTM vignettes. The interviewer recorded the utility value as the point of indifference, as described above. Finally, participants assessed each vignette by rating to what extent they believed the 5 dimensions on the EQ-5D-5L would be affected for a person as described in the vignette. This is referred to as a proxy assessment of the state because the participant is asked to imagine themselves in the health state.

\section{Analysis}

Descriptive statistics were used to summarize sociodemographic information. Means and standard deviations were used for continuous variables. Fre- 
quencies and proportions were used for categorical data.

The VAS ratings for each vignette were rescaled so that the value for the dead state was fixed at zero and all other values varied between 100 and the worse health state. The following formula was used to rescale the data, where $V$ ' is the rescaled VAS value, $V$ is the original VAS value and $V_{\text {Dead }}$ is the value given to the dead state.

$$
V^{\prime}=\left(\frac{V-V_{\text {Dead }}}{100-V_{\text {Dead }}}\right) * 100
$$

TTO data were scored according to the point of indifference. The EQ-5D-5L rating for each state was scored using a mapping function for the EQ-5D-5L and scores reflected UK preference weights [15].

\section{RESULTS}

\section{Qualitative findings}

The qualitative interviews of 5 caregiver parents provided insightful data regarding the impact of XLMTM. Several themes emerged from these descriptive data. Frustration and isolation were often cited as common psychological/emotional impacts of XLMTM. Difficulties communicating with the affected individual was a common cause of frust- ration; therefore, psychological and communication difficulties were referenced in the states. Pain/ discomfort experienced by the patients was also frequently described in the caregiver interviews. Sources of this pain/discomfort included an inability to reposition oneself, certain treatments/procedures, and physical therapy. Ventilatory requirements were also a common theme throughout interviews. All of the caregivers reported that their children required some level of ventilatory support. In addition, respiratoryrelated issues were the most frequently reported impact on patients' daily lives. It also emerged that all patients required assistive devices, most commonly ventilators and gastrointestinal tubes followed by wheelchairs. All patients were largely dependent on caregivers for movement and daily activities, such as dressing, washing, and toileting.

\section{Health state valuation}

\section{Sample characteristics}

Characteristics of the 100 participants who took part in the TTO valuation interviews were approximately representative of the UK population based on the most recent UK census in 2011 (Table 3) [16]. Participants' own health states, as recorded by EQ-5D-5L, are also shown and compared to UK population data from a study that used the EQ-5D-3L

Table 3

Sociodemographic characteristics of the TTO sample of 100 UK residents compared to UK population data

\begin{tabular}{|c|c|c|c|}
\hline Characteristic & & $\begin{array}{c}\text { TTO sample } \\
N=100\end{array}$ & $\begin{array}{c}\text { England \& Wales } \\
\text { population* } \\
N=56,075,912\end{array}$ \\
\hline Age, years & & Mean (SD): $42.6(15.9)$ & Median: 39.4 \\
\hline Interquartile range & & $30.75-51.0$ & - \\
\hline \multirow[t]{2}{*}{ Sex, $\%$} & Female & 53 & 51 \\
\hline & Prefer not to answer & - & - \\
\hline \multirow[t]{4}{*}{ Ethnicity, \% } & White & 84 & 86 \\
\hline & Asian or Asian British & 5 & 8 \\
\hline & Mixed or multiple ethnicity & 6 & 2 \\
\hline & Black/African/Caribbean/Black British & 5 & 3 \\
\hline \multirow[t]{4}{*}{ Occupation, $\%$} & Employed full-time/part time & 66 & 75 \\
\hline & Seeking work/unemployed & 2 & 5 \\
\hline & Student & 19 & 3.4 \\
\hline & Other & 13 & \\
\hline $\begin{array}{l}\text { Long-term health } \\
\quad \text { condition, } n(\%)\end{array}$ & Yes & $20(20)$ & 23 \\
\hline \multirow{6}{*}{$\begin{array}{l}\text { EQ-5D-5L - any } \\
\quad \text { problem, } n(\%)\end{array}$} & Mobility problems & $11(11)$ & $18^{* * *}$ \\
\hline & Self-care problems & $2(2)$ & 4 \\
\hline & Usual activity problems & $14(14)$ & 16 \\
\hline & Pain problems & $24(24)$ & 33 \\
\hline & Anxiety/depression problems & $30(30)$ & 21 \\
\hline & Any dimension problems & $45(45)$ & 43 \\
\hline
\end{tabular}

${ }^{*}$ Data from the 2011 United Kingdom national census [16]; ${ }^{* *}$ Office of National Statistics Labour Force Survey [20]; ${ }^{* * *}$ Data from Kind P et al. [17]. 
Table 4

TTO, EQ-5D and VAS weights for each health state vignette $(N=100)$

\begin{tabular}{lccc}
\hline Health states & $\begin{array}{c}\text { TTO weights } \\
\text { Mean (SD) }\end{array}$ & $\begin{array}{c}\text { EQ-5D-5L } \\
\text { Mean (SD) }\end{array}$ & $\begin{array}{c}\text { VAS } \\
\text { Mean (SD) }\end{array}$ \\
\hline Not able to sit independently & & & \\
$\quad$ Tracheostomy or NIV $>16$ hours & $-0.072(0.542)$ & $-0.270(0.200)$ & $13.4(13.4)$ \\
$\quad$ NIV $<16$ hours & $-0.016(0.510)$ & $-0.253(0.239)$ & $14.8(15.3)$ \\
$\quad$ No ventilation & $0.273(0.450)$ & $-0.122(0.238)$ & $26.2(15.3)$ \\
Able to sit independently & & & \\
$\quad$ Tracheostomy or NIV $>16$ hours & $0.124(0.446)$ & $-0.078(0.259)$ & $21.6(15.5)$ \\
$\quad$ NIV <16 hours & $0.182(0.483)$ & $-0.002(0.271)$ & $22.9(15.2)$ \\
$\quad$ No ventilation & $0.610(0.295)$ & $0.277(0.270)$ & $42.7(19.2)$ \\
Able to stand/walk & & & \\
$\quad$ Tracheostomy or NIV $>16$ hours & $0.282(0.460)$ & $0.292(0.244)$ & $28.2(17.4)$ \\
$\quad$ NIV <16 hours & $0.562(0.340)$ & $0.503(0.214)$ & $43.6(20.6)$ \\
$\quad$ No ventilation & $0.909(0.129)$ & $0.774(0.148)$ & $76.9(16.0)$ \\
\hline NIV non-invasive ventilation. & & &
\end{tabular}

to explore population health [17]. The prevalence of health problems in this sample are broadly comparable to the national sample.

\section{Health state utility weights}

TTO weights for each health state vignette, EQ-5D derived weights and VAS results are shown in Table 4. The low scores indicate how the general public rated the severity of each XLMTM health state. Utility scores for the 2 most severe states were negative, indicating that, on average, the participants considered that these states were worse than dead. The utility scores from the TTO range from -0.072 to 0.909 . The distributional characteristics of the weights for each health state vignette are shown in Table 4 . The values from the EQ-5D proxy evaluation of health states show a similar range to the TTO weights, but the scores for each state are lower. The EQ-5D derived utility values from ranged from -0.270 to 0.774 .

\section{DISCUSSION}

This report describes work to estimate utility weights for XLMTM health states that can be useful to families, clinicians, and regulators in evaluating the risk-benefit balance associated with novel treatments, such as AAV-based gene therapy. They may also be used in economic analyses. The study employed the vignette methodology with the general public rating each state using the TTO method, the VAS, and a proxy valuation EQ-5D. The ratings from the 3 methods were broadly consistent with one another, especially in terms of the differences between the states.

The vignette method for estimating utility weights relies heavily upon the accuracy of the health state descriptions. In rare, debilitating diseases such as XLMTM, capturing utility data using direct assessment of affected individuals is precluded by challenges related to recruitment and disability caused by the disease itself. To address this limitation of vignette methods, the present study focused primarily on development of the health state vignettes. These health states were informed by several comprehensive natural history studies [4-7], as well as the caregiver and clinical expert interviews. Vignettes were generated from multiple independent sources of information including the ACEND data from the ASPIRO study which describes functional status in XLMTM. Information regarding the psychosocial impact and pain associated with XLMTM was established qualitatively from parent interviews. Input was also captured from leading clinical experts on the nature of XLMTM and the accuracy of the states. The ordering and magnitude of the weights from the valuation exercise also support the content validity of the vignettes as good estimates of the HRQL burden of XLMTM.

The resultant weights for each state derived from the TTO, VAS, and EQ-5D assessments demonstrate a consistent pattern. The range of scores is broad and indeed some states with the most severe limitations have health utility weights near or below 0 . Such low values suggest that states have a value which is similar to being dead or even worse than death. This is in no way a judgement on people with XLMTM, nor does it imply that a life with XLMTM is in some way not worth living. The participants in this exercise were not told that the states described XLMTM and indeed were given very little information as to why they had this level of functional problems. Rather, these findings reflect the views of the general public regarding the severity of the burden of XLMTM. Health 
states from another severe neuromuscular disease that can severely limit respiratory and physical function, spinal muscular atrophy (SMA), were similar. Several studies have explored the natural history of SMA, most notably perhaps is Chabanon et al., who reported that muscle imaging, functional status, and clinician assessment generally correlate with each other [18]. In a survey of parents of children with SMA type 2 , the mean health utility score was -0.012 and parents' HRQL was 0.472 , which is greatly reduced from what would otherwise be expected based on age (typically above 0.90 for adults) [19]. Another study based only on expert ratings of vignettes reported values for SMA type 2 states ranging from -0.13 to 0.72 [12]. Thus, health states associated with SMA are consistent with those reported for XLMTM in the current study and reflect a general understanding of the substantial disease burden shared by these severe neuromuscular disorders.

This work's limitations should be considered when interpreting results. While the vignette methodology allows for estimation of utility weights for any state, including states which are rarely or never seen clinically but may become more common with new therapies, there is a risk that some vignette descriptions may be too severe, not severe enough, or missing important disease aspects that are typically experienced. It is also possible that the vignettes over- or under-emphasize aspects of the disease. To maximize the content validity of the vignettes, multiple sources of information were utilized to guide their content development (i.e., qualitative interview data from families, parent-reported data from the ASPIRO clinical trial, and clinical expert opinion). Three states defined in the model have little or no data to support their content development: (1) able to stand/walk and no ventilation dependence; (2) able to stand/walk and requiring non-invasive ventilation $<16$ hours; and (3) unable to sit independently and no ventilation assistance. Instead, the descriptions were generated by extrapolating content from states where data were available and based on potential responses to therapy informed in part by published data on SMA treatment and experience from clinical experts who also treat patients with SMA. Although these descriptions were reviewed by the clinical experts in terms of face validity, the utility weights for these states have a higher degree of uncertainty. If effective, intervention studies for XLMTM will provide an opportunity to verify the utility weights for states not yet attained in this patient population. Lastly the methodology requires members of the public to try to imagine life as described in the vignette. Given the severity of the states in terms of the burden of XLMTM we believe that this was a challenging task for participants. Indeed, it is possible that the public do not reflect on how patients and their families learn to cope and adjust to the limitations that they experience.

\section{CONCLUSIONS}

These study findings indicate that XLMTM patients can experience a large utility decrement. An effective XLMTM treatment could be expected to have a meaningful impact on patients' quality-of-life.

\section{ACKNOWLEDGMENTS}

The authors thank the study participants and XLMTM patient and family community, and in particular the The Myotubular Trust, the Joshua Frase Foundation, MTM-CNM Family Connection, Where There's a Will There's A Cure Foundation for Myotubular Myopathy, and ZNM - Zusammen Stark! for ongoing participation and support. This study was funded by Astellas Gene Therapies (previously Audentes Therapeutics). Additional support for collection of phenotypic and outcomes information was provided by the Muscular Dystrophy Association (USA) grant MDA602235 and the Joshua Frase Foundation to AHB.

\section{CONFLICT OF INTEREST}

$\mathrm{AL}$ and DA are employees and shareholders of Acaster Lloyd Consulting, Ltd.. TLS is an employee and shareholders of Astellas Gene Therapies (previously Audentes Therapeutics). JL is an ex-employee of Astellas Gene Therapies. AHB has received sponsored research support from Alexion, Dynacure and Pfizer, personal fees from Audentes, Ballard Biologics, Biogen, GLG, Guidepoint Global, Kate, and Roche, equity in Ballard Biologics and Kate. DB had served on a scientific advisory board for Astellas Gene Therapies (fomerly Audentes Therapeutics and is a consultant for BioMarin Pharmaceuticals, Encoded Therapeutics, and Taysha Gene Therapies.

\section{REFERENCES}

[1] Dowling JJ, Lawlor MW, Das S. X-Linked Myotubular Myopathy. In: Adam MP, Ardinger HH, Pagon RA, Wallace SE, Bean LJH, Stephens K, et al., editors. 
GeneReviews((R))1993-2019 [updated 2018 Aug 23]. Seattle (WA) 2002.

[2] Hnia K, Vaccari I, Bolino A, Laporte J. Myotubularin phosphoinositide phosphatases: Cellular functions and disease pathophysiology. Trends Mol Med. 2012;18(6):317-27.

[3] Vandersmissen I, Biancalana V, Servais L, Dowling JJ, Vander Stichele G, Van Rooijen S, et al. An integrated modelling methodology for estimating the prevalence of centronuclear myopathy. Neuromuscul Disord. 2018;28(9):766-77.

[4] McEntagart M, Parsons G, Buj-Bello A, Biancalana V, Fenton I, Little M, et al. Genotype-phenotype correlations in X-linked myotubular myopathy. Neuromuscul Disord. 2002;12(10):939-46.

[5] Amburgey K, Tsuchiya E, de Chastonay S, Glueck M, Alverez R, Nguyen CT, et al. A natural history study of X-linked myotubular myopathy. Neurology. 2017;89(13): 1355-64.

[6] Beggs AH, Byrne BJ, De Chastonay S, Haselkorn T, Hughes I, James ES, et al. A multicenter, retrospective medical record review of X-linked myotubular myopathy: The RECENSUS study. Muscle Nerve. 2018;57(4):550-60.

[7] Graham RJ, Muntoni F, Hughes I, Yum SW, Kuntz NL, Yang ML, et al. Mortality and respiratory support in Xlinked myotubular myopathy: A RECENSUS retrospective analysis. Arch Dis Child. 2020;105(4):332-8.

[8] Annoussamy M, Lilien C, Gidaro T, Gargaun E, Che V, Schara U, et al. X-linked myotubular myopathy: A prospective international natural history study. Neurology. 2019;92(16):e1852-e67.

[9] Bönnemann CG, Shieh PB, Kuntz NL, Müller-Felber W, Blaschek A, Foley AR, et al. ASPIRO Gene Therapy Trial In X-Linked Myotubular Myopathy (XLMTM): Update on Safety And Efficacy. World Muscle Society Virtual Congress 2020. (manuscript in preparation)

[10] Sansone VA, Pirola A, Albamonte E, Pane M, Lizio A, D'Amico A, et al. Respiratory Needs in Patients with Type 1 Spinal Muscular Atrophy Treated with Nusinersen. J Pediatr. 2020;219:223-8.e4.

[11] Matsumoto H, Clayton-Krasinski DA, Klinge SA, Gomez JA, Booker WA, Hyman JE, et al. Development and initial validation of the assessment of caregiver experience with neuromuscular disease. J Pediatr Orthop. 2011;31(3): 284-92.
[12] Lloyd AJ, Thompson R, Gallop K, Teynor M. Estimation Of The Quality Of Life Benefits Associated With Treatment For Spinal Muscular Atrophy. Clinicoecon Outcomes Res. 2019;11:615-22.

[13] Drummond MF, McGuire A. Economic Evaluation in Health Care: Merging Theory with Practise. Oxford, New York: Oxford University Press; 2001.

[14] Torrance GW. Measurement of health state utilities for economic appraisal. J Health Econ. 1986;5(1):1-30.

[15] van Hout B, Janssen MF, Feng YS, Kohlmann T, Busschbach J, Golicki D, et al. Interim scoring for the EQ-5D-5L: Mapping the EQ-5D-5L to EQ-5D-3L value sets. Value Health. 2012;15(5):708-15.

[16] Office for National Statistics. 2011 Census: Key Statistics and Quick Statistics for Local Authorities in the United Kingdom 2011 [Available from: https://www.ons. gov.uk/employmentandlabourmarket/peopleinwork/emplo ymentandemployeetypes/bulletins/keystatisticsandquickst atisticsforlocalauthoritiesintheunitedkingdom/2013-12-04.

[17] Kind P, Dolan P, Gudex C, Williams A. Variations in population health status: Results from a United Kingdom national questionnaire survey. BMJ. 1998;316(7133):736-41.

[18] Chabanon A, Seferian AM, Daron A, Pereon Y, Cances $\mathrm{C}$, Vuillerot $\mathrm{C}$, et al. Prospective and longitudinal natural history study of patients with Type 2 and 3 spinal muscular atrophy: Baseline data NatHis-SMA study. PLoS One. 2018;13(7):e0201004.

[19] Lopez-Bastida J, Pena-Longobardo LM, Aranda-Reneo I, Tizzano E, Sefton M, Oliva-Moreno J. Social/economic costs and health-related quality of life in patients with spinal muscular atrophy (SMA) in Spain. Orphanet J Rare Dis. 2017;12(1):141.

[20] Office for National Statistics. Employment in the UK: January 2021 Estimates of employment, unemployment and economic inactivity for the UK. 2021 [Available from: https://www.ons.gov.uk/employmentandlabourmarket/peo pleinwork/employmentandemployeetypes/bulletins/empl oymentintheuk/latest. 
APPENDIX

Table A.1. Expert comments and health state description modifications

\begin{tabular}{|c|c|c|}
\hline Domain/concept & Comment & Modification \\
\hline \multirow[t]{4}{*}{ Eat/wash/dress } & $\begin{array}{l}\text { Amount of therapy may not be correlated with } \\
\text { severity. Amount of therapy is multifactorial } \\
\text { (interviews } 1 \& 4 \text { ) }\end{array}$ & $\begin{array}{l}\text { Removed item relating to physical therapy. } \\
\text { Treatments related to clearing } \\
\text { secretions/saliva moved to breathing domain }\end{array}$ \\
\hline & $\begin{array}{l}\text { Eating/drinking problems are caused by two } \\
\text { factors: muscle weakness and swallowing } \\
\text { difficulties (interviews } 4 \& 5 \text { ) }\end{array}$ & $\begin{array}{l}\text { Reworded eating/drinking item highlighting that } \\
\text { problems may be caused by muscle weakness } \\
\text { or swallowing or both }\end{array}$ \\
\hline & $\begin{array}{l}\text { Clarify that patients are usually continent but } \\
\text { may not physically be able to get to the toilet } \\
\text { (interviews } 3 \& 4 \text { ) }\end{array}$ & $\begin{array}{l}\text { Reworded to clarify that the difficulty is getting } \\
\text { to the toilet }\end{array}$ \\
\hline & $\begin{array}{l}\text { Most severe states require diapers (interviews } \\
3 \text { \& 4) }\end{array}$ & $\begin{array}{l}\text { Added the requirement of an incontinence pad to } \\
\text { most severe states }\end{array}$ \\
\hline Sitting/movement & $\begin{array}{l}\text { Emphasize inability to move/reposition oneself } \\
\text { (interview } 3 \text { \& 5) }\end{array}$ & $\begin{array}{l}\text { Added text to emphasize inability to } \\
\text { move/reposition in those unable to sit }\end{array}$ \\
\hline \multirow[t]{4}{*}{ Mobility } & $\begin{array}{l}\text { Clarify that the most severe states are not able to } \\
\text { stand/walk (interview 1) }\end{array}$ & Added text to clarify inability to stand/walk \\
\hline & $\begin{array}{l}\text { Crawling is particularly challenging. Most } \\
\text { severe states would not be able to crawl. } \\
\text { Scoot/shuffle more appropriate (interview 3) }\end{array}$ & Crawl changed to shuffle \\
\hline & $\begin{array}{l}\text { Mobility is limited by amount of ventilatory and } \\
\text { monitoring equipment (interview } 2,3 \& 4 \text { ) }\end{array}$ & $\begin{array}{l}\text { Added text to states with most ventilation to } \\
\text { emphasize restricted mobility due to } \\
\text { equipment }\end{array}$ \\
\hline & $\begin{array}{l}\text { Least severe states may still require assistive } \\
\text { devices to get around for most of the day } \\
\text { (interview } 1 \& 3 \text { ) }\end{array}$ & $\begin{array}{l}\text { Added text to highlight need for walking aids in } \\
\text { states that are able to stand/walk and require } \\
\text { ventilation }\end{array}$ \\
\hline Pain/discomfort & $\begin{array}{l}\text { Emphasize that pain/discomfort is due to } \\
\text { inability to reposition (interviews } 3 \& 5 \text { ) }\end{array}$ & $\begin{array}{l}\text { Added some context to describe source of pain } \\
\text { discomfort }\end{array}$ \\
\hline \multirow[t]{4}{*}{$\begin{array}{l}\text { Psychological/ } \\
\text { communication }\end{array}$} & $\begin{array}{l}\text { Even most severe patients can talk/vocalize, but } \\
\text { will be at a low volume and sometimes } \\
\text { unclear (interviews } 1 \& 4 \text { ) }\end{array}$ & $\begin{array}{l}\text { Reworded to clarify that even most severe states } \\
\text { may be able to talk but not with normal } \\
\text { volume/clarity }\end{array}$ \\
\hline & $\begin{array}{l}\text { Speech largely determined by ventilation status, } \\
\text { but may also be improved with better physical } \\
\text { function (interviews } 1,2 \& 5 \text { ) }\end{array}$ & $\begin{array}{l}\text { Descriptions were aligned primarily according } \\
\text { to ventilation status }\end{array}$ \\
\hline & $\begin{array}{l}\text { Emphasize difficulties describing pain and } \\
\text { calling out when in need of assistance } \\
\text { (interviews } 3 \& 5 \text { ) }\end{array}$ & $\begin{array}{l}\text { Added statement to most severely ventilated } \\
\text { states }(>16 \mathrm{hr} \text { or trach and }<16 \mathrm{hr} \text { ventilation }) \\
\text { to describe these difficulties }\end{array}$ \\
\hline & $\begin{array}{l}\text { Sadness may not be predictable/appropriate } \\
\text { (interviews } 1,2 \& 5 \text { ) }\end{array}$ & $\begin{array}{l}\text { Replaced sadness statements with 'emotional } \\
\text { distress' }\end{array}$ \\
\hline Ventilation & $\begin{array}{l}\text { Emphasize reliance on ventilation equipment } \\
\text { and other treatments in order to breathe } \\
\text { (interviews } 2 \text { \& 5) }\end{array}$ & $\begin{array}{l}\text { Added text to highlight difficulties } \\
\text { coughing/swallowing and treatment required } \\
\text { in order to clear airways in states that required } \\
\text { the most ventilation/trach }\end{array}$ \\
\hline
\end{tabular}


Table A.2. Health states

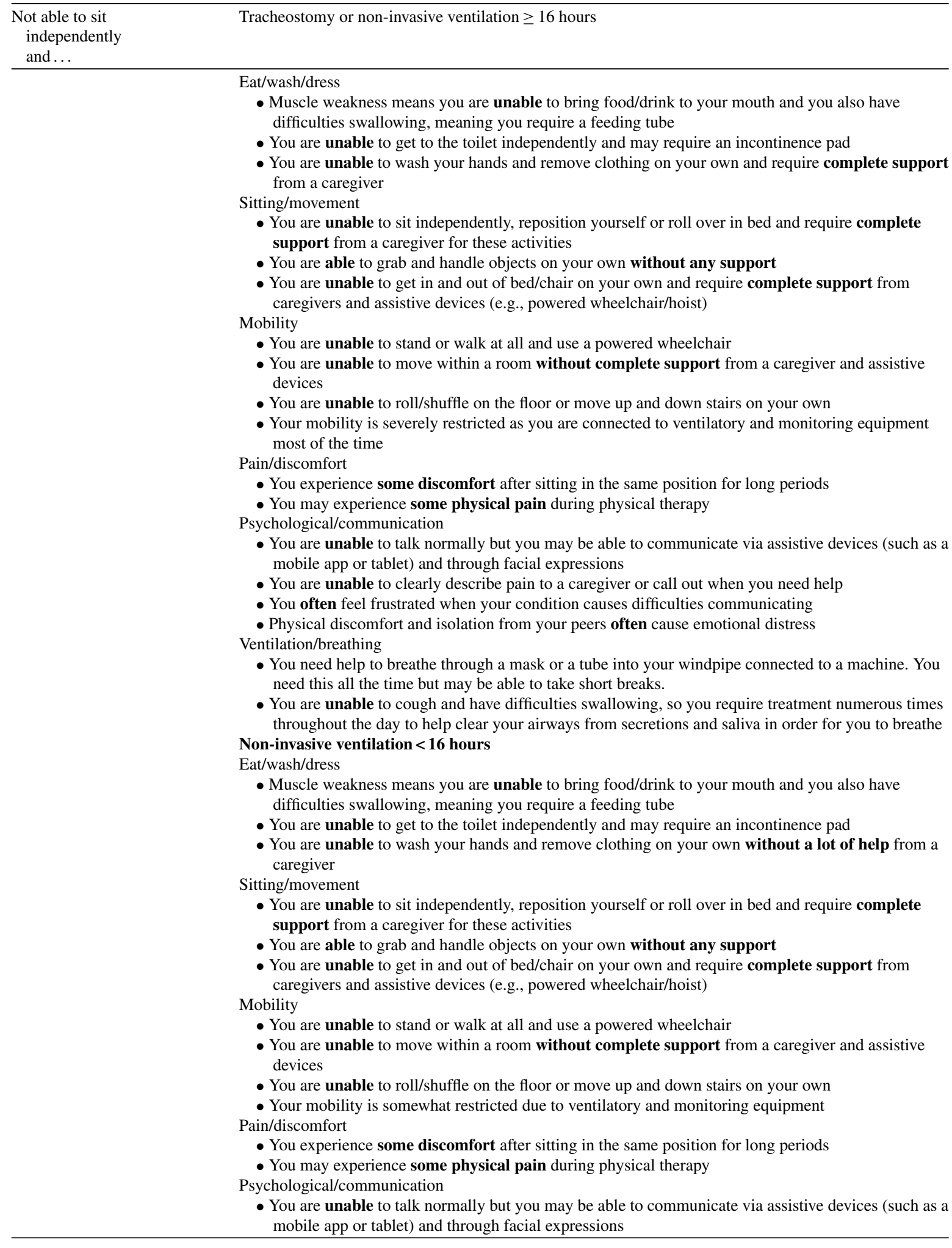


Table A.2.

(Continued)

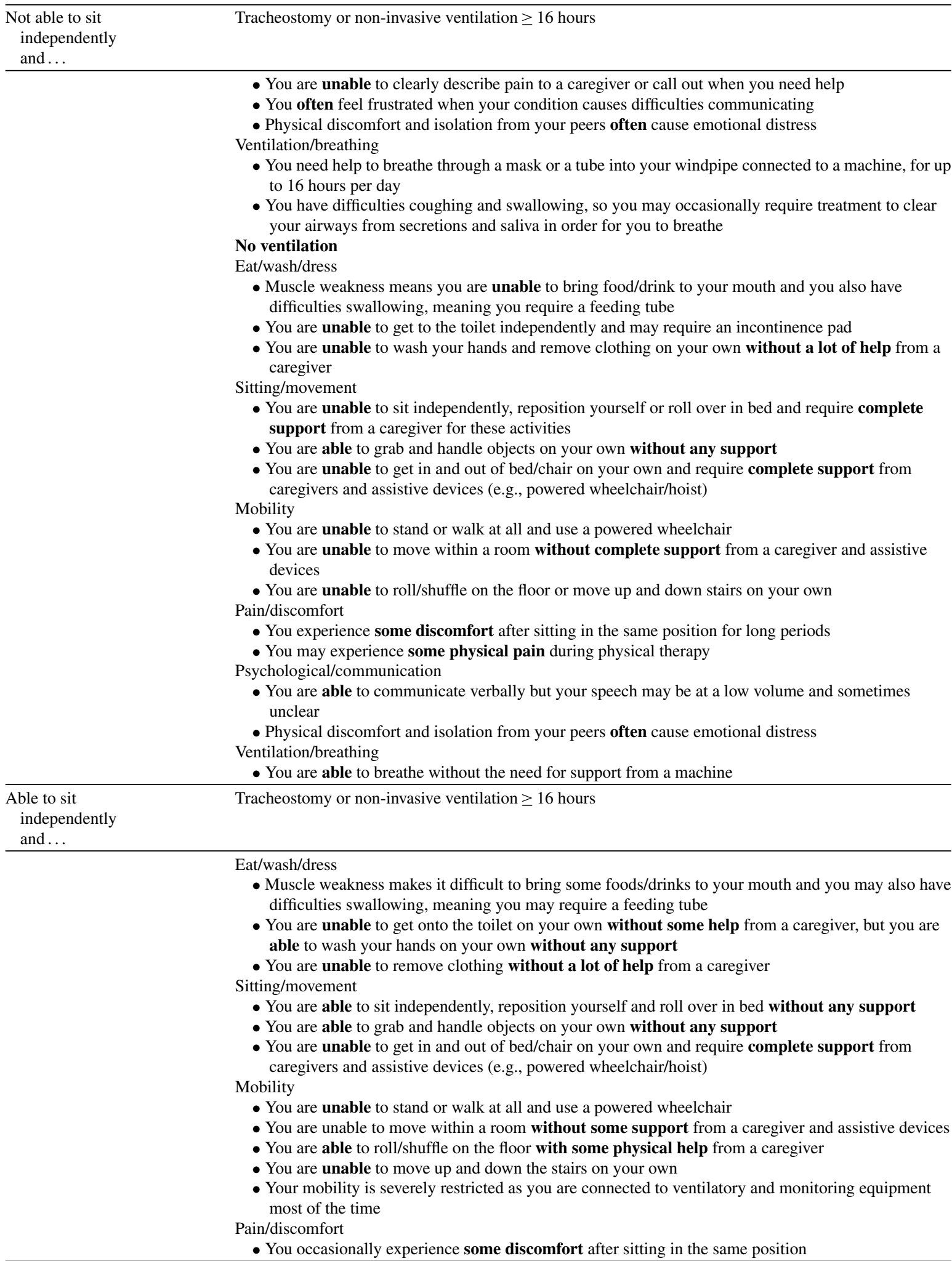


Table A. 2

(Continued)

\begin{tabular}{|c|c|}
\hline $\begin{array}{l}\text { Not able to sit } \\
\text { independently } \\
\text { and... }\end{array}$ & Tracheostomy or non-invasive ventilation $\geq 16$ hours \\
\hline & 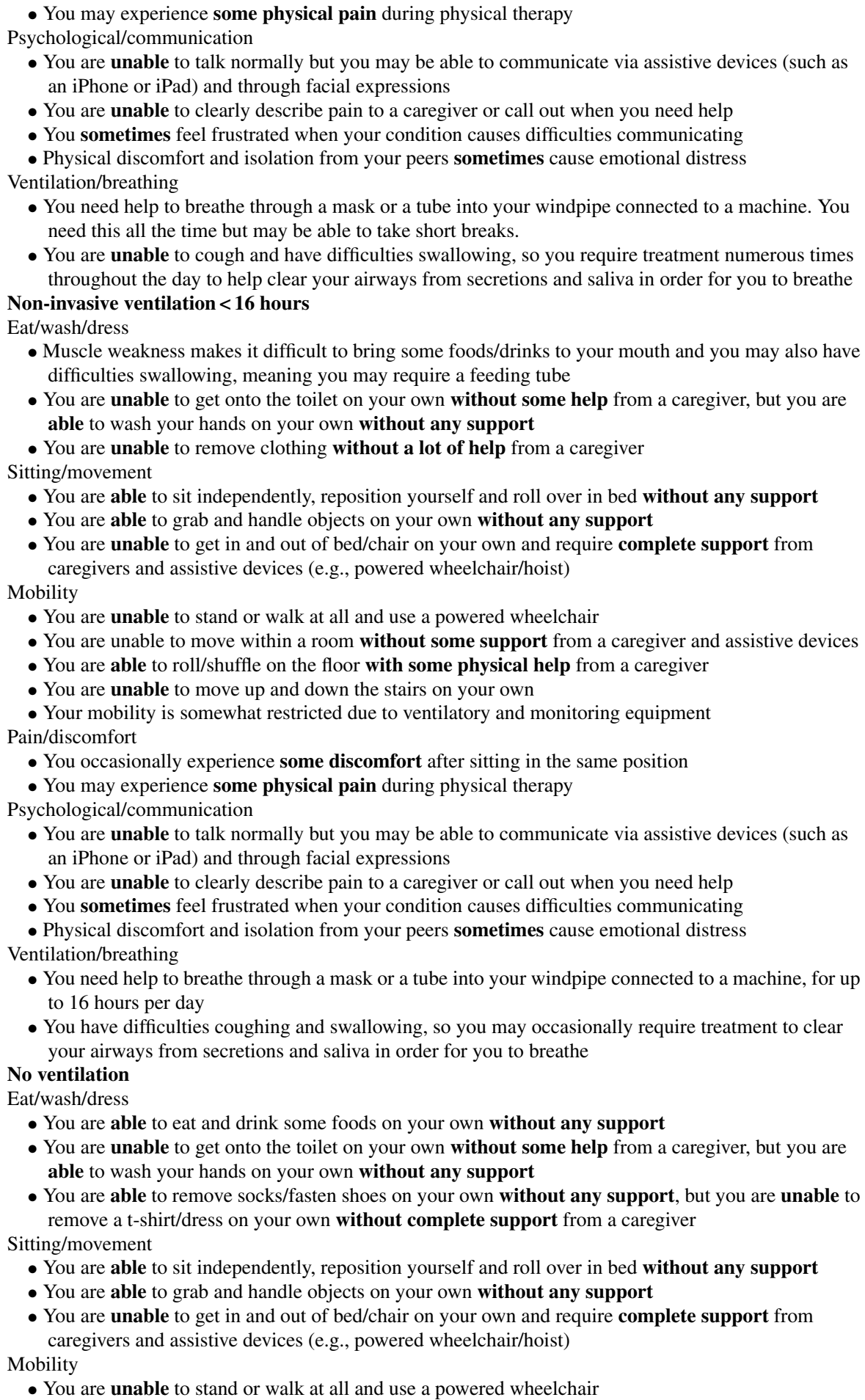 \\
\hline
\end{tabular}


Table A.2.

(Continued)

\begin{tabular}{|c|c|}
\hline \multirow[t]{2}{*}{$\begin{array}{l}\text { Not able to sit } \\
\text { independently } \\
\text { and... } \\
\end{array}$} & Tracheostomy or non-invasive ventilation $\geq 16$ hours \\
\hline & $\begin{array}{l}\text { - You are unable to move within a room without some support from a caregiver and assistive devices } \\
\text { - You are able to roll/shuffle on the floor with some physical help from a caregiver } \\
\text { - You are unable to move up and down the stairs on your own } \\
\text { Pain/discomfort } \\
\text { - You occasionally experience some discomfort after sitting in the same position } \\
\text { - You may experience some physical pain during physical therapy } \\
\text { Psychological/communication } \\
\text { - You are able to communicate verbally but your speech may be at a low volume and sometimes } \\
\text { unclear } \\
\text { - Physical discomfort and isolation from your peers sometimes cause emotional distress } \\
\text { Ventilation/breathing } \\
\text { - You are able to breathe without the need for support from a machine }\end{array}$ \\
\hline $\begin{array}{l}\text { Able to stand/walk } \\
\text { and ... }\end{array}$ & Tracheostomy or non-invasive ventilation $\geq 16$ hours \\
\hline & 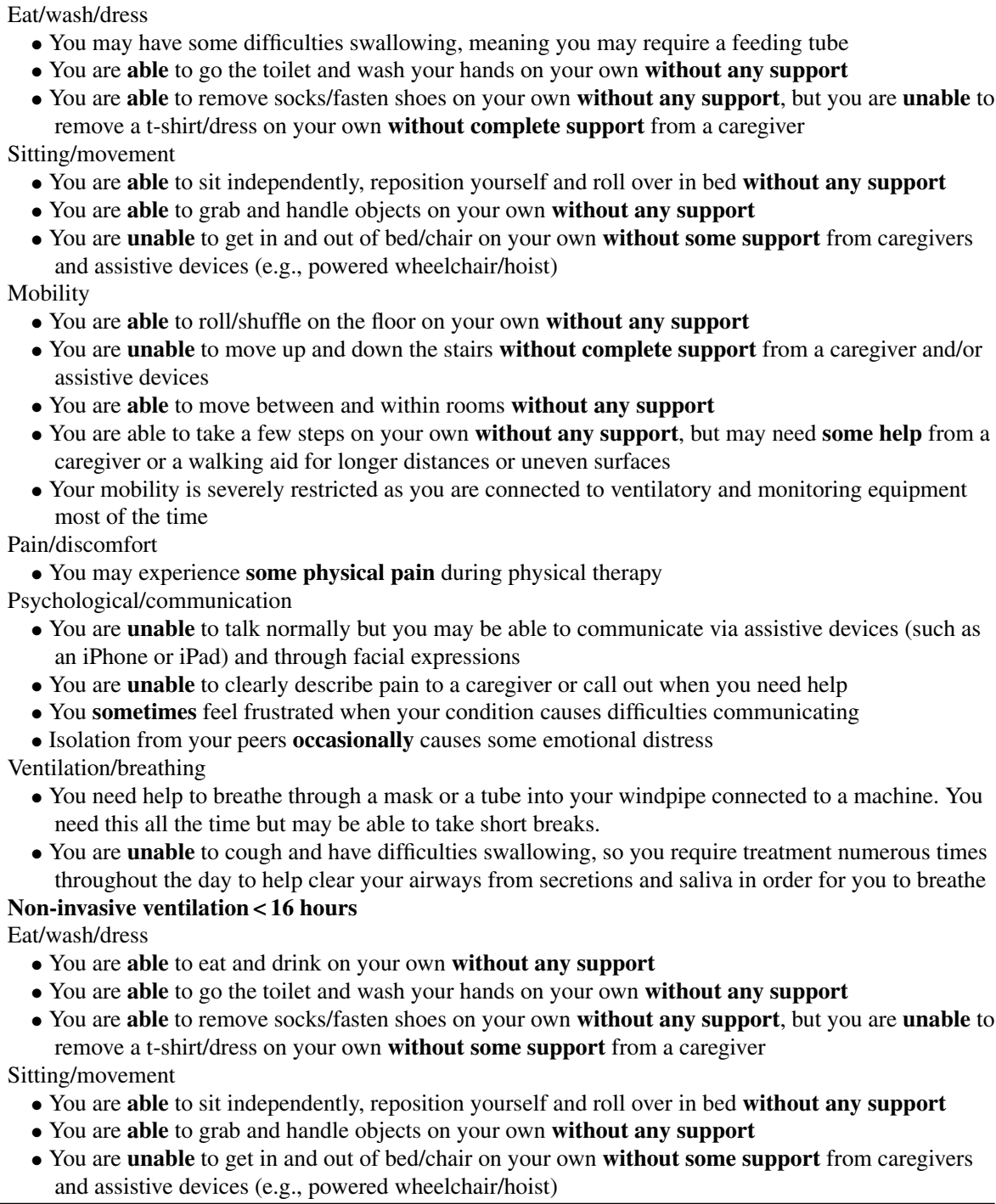 \\
\hline
\end{tabular}


Table A. 2

(Continued)

\begin{tabular}{|c|c|}
\hline $\begin{array}{l}\text { Not able to sit } \\
\text { independently } \\
\text { and... }\end{array}$ & Tracheostomy or non-invasive ventilation $\geq 16$ hours \\
\hline & 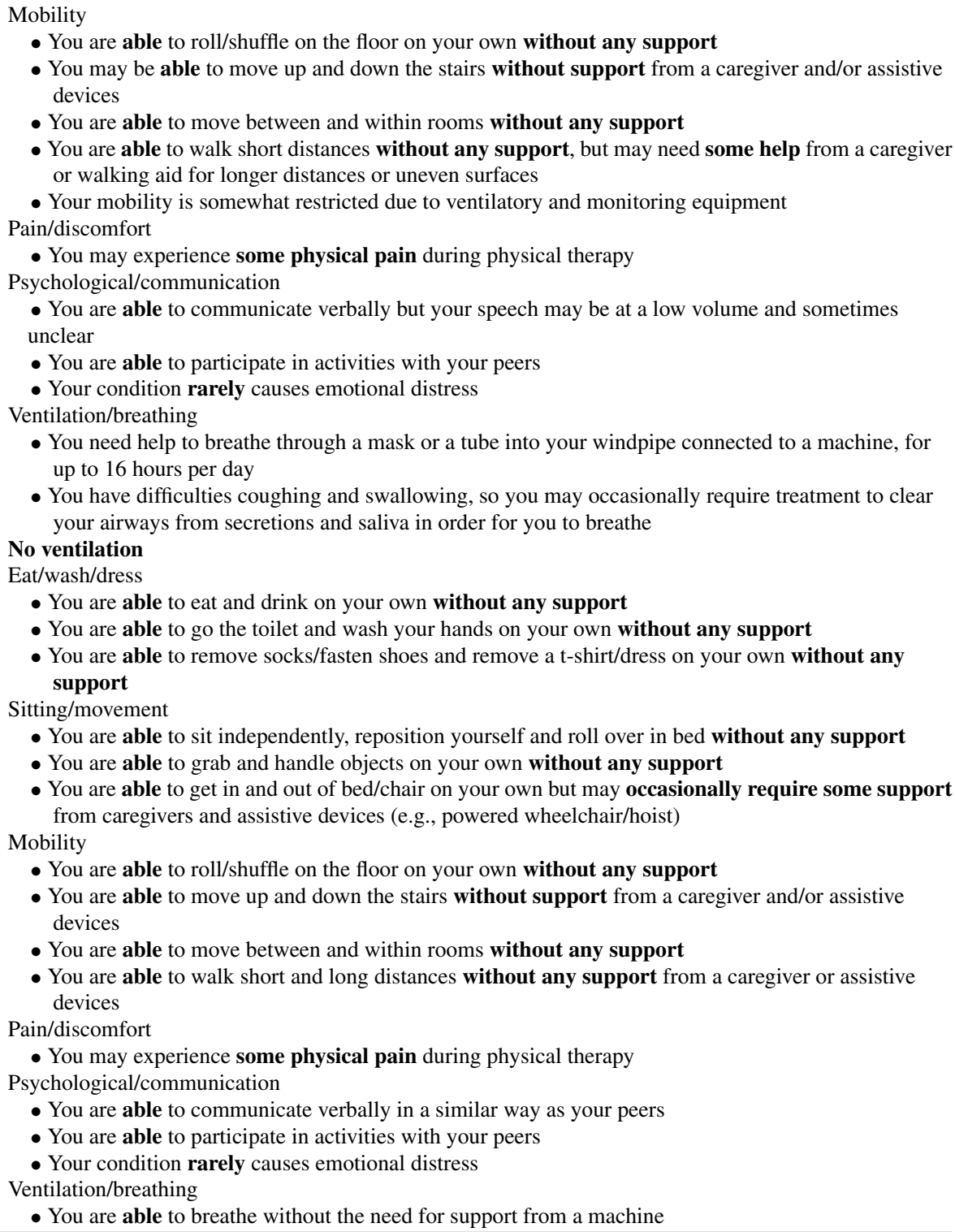 \\
\hline
\end{tabular}

